\title{
Motivation of Women Academics and Balancing Family \& Career
}

\author{
Dr. Pamela Adhiambo Raburu \\ Department of Psychology \& Educational Foundations, School of Education, \\ Jaramogi Oginga Odinga University of Technology (JOOUST), P.O. Box 210-40601, Bondo- Kenya \\ Email: praburu@jooust.ac.ke
}

\section{Doi:10.5901/jesr.2015.v5n1p359}

\begin{abstract}
This study examines the experiences of women academics in relation to factors that motivated them towards academia and challenges experienced while balancing family and career, and highlighting strategies that they have employed to reach their present professional and academic ranks. The study is a contribution to knowledge and the extant literature on women academics' career experiences which has been under-researched, especially in Kenya. It claims to have made a contribution to a wider understanding of women academics' experiences, exposing a significant impact of culture, family -work tensions, the gender role expectations, the male-dominated university culture, lack of role models and mentors, which contribute to the slow progress of women academics' careers in Kenyan universities. Using a qualitative research approach, the researcher used a face -to -face in- depth interviews with sixteen women academics from three universities in Kenya and thematic analysis used. The findings of this research demonstrated that very few women have progressed into senior academic and professional ranks and that, the pace is slow. They continue to be hampered by the socio-cultural attitude towards women and their roles in the Kenyan society. This is not the full story as some of the women interviewed reported that they had to put off marriage for career and likewise, others put on hold or postponed career for family responsibilities. To maintain their positions or climb the professional ladder, the women academics therefore, had to employ different strategies such as; working hard, focusing on research and publication for promotion purposes. The findings further shed light to policy makers, stake holders in higher institutions of learning and the world of academia, while filling the knowledge gap.
\end{abstract}

Keywords: motivation, challenges, career, higher education, women academics, gender

\section{Introduction}

A substantial research on women academics and career advancement in western countries has been produced in Australia, United Kingdom, Canada and United States of America in the past years (Acker and Armenti, 2004; White, 2004; Aisenberg and Harrington, 1988; Morley, 2000; Morley, 2006; Armenti, 2004b; Bagilhole, 1993a; Blackmore, 1999). Internationally, women have been identified as a group in need of inclusion into the private and public sectors that higher education can offer (Morley and Lugg, 2009). The few studies which have been conducted in Kenya on women in higher education include; gender disparities Kanake (1997),, research and publication, Onsongo (2000), women's participation in university management, Onsongo (2005) and equal opportunity policy Manya (2000). The only existing study on women's academics' career experiences was that by Kamau (2004).

According to Forster (2001), there are other factors such as the structural and socio-cultural that block female academics from a smooth career advancement. The under-representation of women academics is not unique to Kenya, as shown by research on women in Higher Education over the past decades in Western countries. Despite the widespread introduction of equal opportunity policies in $\mathrm{HE}$, women have not been notably more successful in reaching senior positions in academe (Forster, 2001).

To highlight the contemporary situation in Kenyan universities, the study examined faculty profiles from the university websites and from the registry in Table 1 and Table 2 below which show the under-representation of women academics. 
Table 1: Professional Ranks at Universities $X, Y$ and $Z$

\begin{tabular}{|l|c|c|c|c|c|c|}
\hline \multirow{2}{*}{ Professional Rank } & \multicolumn{2}{|c|}{ University X } & \multicolumn{2}{c|}{ University Y } & \multicolumn{2}{c|}{ University Z } \\
\cline { 2 - 7 } & Sex & Total & Sex & Total & Sex & Total \\
\hline \multirow{2}{*}{ Full Professor } & $\mathrm{M}$ & 15 & $\mathrm{M}$ & 16 & $\mathrm{M}$ & 03 \\
\cline { 2 - 7 } & $\mathrm{F}$ & 02 & $\mathrm{~F}$ & 03 & $\mathrm{~F}$ & 00 \\
\hline \multirow{2}{*}{ Associate Professors } & $\mathrm{M}$ & 17 & $\mathrm{M}$ & 09 & $\mathrm{M}$ & 04 \\
\cline { 2 - 7 } & $\mathrm{F}$ & 01 & $\mathrm{~F}$ & 05 & $\mathrm{~F}$ & 00 \\
\hline \multirow{2}{*}{ Senior Lecturers } & $\mathrm{M}$ & 39 & $\mathrm{M}$ & 63 & $\mathrm{M}$ & 09 \\
\cline { 2 - 7 } & $\mathrm{F}$ & 9 & $\mathrm{~F}$ & 22 & $\mathrm{~F}$ & 05 \\
\hline \multirow{2}{*}{ Lecturers } & $\mathrm{M}$ & 75 & $\mathrm{M}$ & 95 & $\mathrm{M}$ & 10 \\
\hline \multirow{2}{*}{ Assistant Lecturers } & $\mathrm{F}$ & 27 & $\mathrm{~F}$ & 23 & $\mathrm{~F}$ & 06 \\
\hline Total & $\mathrm{M}$ & 92 & $\mathrm{M}$ & 111 & $\mathrm{M}$ & 12 \\
\cline { 2 - 7 } & $\mathrm{F}$ & 38 & $\mathrm{~F}$ & 63 & $\mathrm{~F}$ & 09 \\
\hline
\end{tabular}

Sources: University registry and websites, January 2010

Table 2: Academic Ranks at Universities $X, Y$ and $Z$

\begin{tabular}{|l|c|c|c|c|c|c|}
\hline Academic Rank & \multicolumn{2}{|c|}{ University X } & \multicolumn{2}{c|}{ University Y } & \multicolumn{2}{c|}{ University Z } \\
\hline \multirow{2}{*}{ PhD } & $\mathrm{M}$ & 100 & $\mathrm{M}$ & 163 & $\mathrm{M}$ & 16 \\
\cline { 2 - 7 } & $\mathrm{F}$ & 24 & $\mathrm{~F}$ & 39 & $\mathrm{~F}$ & 05 \\
\hline \multirow{2}{*}{ Masters } & $\mathrm{M}$ & 138 & $\mathrm{M}$ & 133 & $\mathrm{M}$ & 22 \\
\cline { 2 - 7 } & $\mathrm{F}$ & 53 & $\mathrm{~F}$ & 75 & $\mathrm{~F}$ & 15 \\
\hline Total & & 315 & & 410 & & $\mathbf{5 8}$ \\
\hline
\end{tabular}

Sources: University registry and websites, January 2010

The data of the faculty profiles in Tables 1 and 2 show that women are still under-represented in academia in Kenya in 2010. It appears that even those few get fewer as they ascend to senior ranks, with majority in Assistant lecturers and Lecturers ranks. At university $Z$, there is no women professor, not even an Associate professor. Universities $X$ and $Y$ have 2 and 3 female professors respectively. These figures raise significant questions about the role of women academics in Higher Education in Kenya, and in particular, why are there so few women academics, and more so, senior ones? Why have women's high educational achievement levels not produced greater female representations in the university sector? These questions continue to be pertinent, and they point to a gap in current scholarly knowledge, that requires further research. Since the literature on women academics in Kenya is extremely scarce, the literature review includes substantial references to studies of female academics in other countries like United Kingdom, United States of America, Australia, and Canada and South Africa.

On a global context, women at the senior levels in academia have not achieved a critical mass (White, 2001) despite the existence of equity programmes in universities for the last few decade. According to White (2001), being a female senior in academia in Australia is a hard road to travel, and it can be harder still to even reach that point. She further indicates that while the number of women professors in Australia has increased over the last decades, universities still have a disproportionately small number of senior women. Although the numbers of women in higher education are rising in many countries, most occupy part-time, low-status or temporary positions and the proportion of women in most senior academic positions remains small (Mason and Goulden, 2002). According to (Forster, 2001; Bagilhole, 1993a) there are structural and socio-cultural barriers for women in academia as they advance their careers.

Among the reasons as barriers that impede career motivation include; family conflicts and work structural barriers recruitment and selection policies, lack of mentors and role models, promotion policies and institutional male power (Luke, 2000). Bagilhole (1993b) also found that women tend to have higher lecturing, administration and counseling workloads compared to men. However, these duties are overlooked in the promotion process that emphasise almost exclusively research and publication outputs (Forster, 2001; Onsongo, 2000). According to Morley (2006), such factors that impede women's career progress in academia include; the exclusion of women from career development opportunities, gender-insensitive pedagogical processes, prejudice about women's academic abilities and intellectual 
authority, poor equality policy implementation and backlash and stigmatisation in relation to affirmative action programmes.

In Kenya, women's under-representation in academia remains startling, women accounting for $7.1 \%$ of professors (Manya, 2000). Gachukia (2002, p.3) further emphases the continuing under-representation of women academics in Kenya's public universities:

Kenyatta University had one woman Deputy Vice Chancellor, and among full professors, there were 2 women out 24 professors. Moi University had only one woman professor of 37 professors. Out of 65 lecturers, there were only 6 women. There were 50 women Lecturers out of the total 417 in all public universities.

Table 3 contains statistics on professors in Kenyan public universities by their gender

Table 3: The Number of Professors in Kenya's Public Universities

\begin{tabular}{lcc}
\hline University & Male & Female \\
\hline Nairobi & 100 & 10 \\
Egerton & 9 & 0 \\
Masinde Muliro & 10 & 1 \\
Kenyatta University & 28 & 2 \\
Maseno & 15 & 2 \\
JKUAT & 17 & 5 \\
Moi & 31 & 4 \\
Constituents & 3 & 0 \\
\hline Total & $\mathbf{2 1 3}$ & $\mathbf{2 4}$ \\
\hline
\end{tabular}

Source: The Daily Nation $7^{\text {th }}$ November 2010 (Commission for Higher Education-Kenya)

Table 3 shows the under-representation although a slight increase in the number of women professors to $10 \%$ from what Manya (2000) reported at $7.1 \%$.

A low enrolment rate of girls and women is still a challenge in university education in Kenya. This is despite the affirmative action policy that allows girls to be admitted at state universities with one point lower than that of boys (Onsongo, 2009). Onsongo (2009, p.71) in her study reported that the 'affirmative action as currently applied does not enhance access and gender equity in university education'. It was reported that 1,070 girls were admitted to the university with two points lower than their male counterparts, on what the JAB (Joint Admission Board) termed as part of the affirmative action policy aimed at attaining gender parity and to ensure females entered the university (Siringi, 2009). Another of the challenges faced by women academics in Kenya, as elsewhere, is the highly masculinist culture and several gate- keepers in the highly hierarchical management exhibited by the universities (Manya, 2000, p.9). She contends:

I signed my name as M.Manya, Snr. Administrative Assistant with no indication of my gender. In response, the chairman (male) addressed the envelope and my letter as 'Mr. M. Manya'. It left me quite amused, but made me wonder why the assumption that I was male was made.

The socialisation process in Kenya and the societal allocation of role wife/mother, care giver to the women has also further exacerbated women's limitations to career advancement (Onsongo, 2005). Girls are socialized to expect marriage and bear children. Only a small proportion of girls enroll for postgraduate courses. According to 1999/2000 figures, women constituted $29.5 \%$ at the university of Nairobi with a mere $24 \%$ in postgraduate courses (Nyamu, 2004). There were only three female Professors then, constituting $5.1 \%$ showing an increase yet still too few. It is from this scattered pool of women that senior appointments can be made.

This study relates motivation to the women's career advancement in terms of those factors that facilitated their career success and how sources of motivation could be embedded in their gender roles and socialization which later impact on their career decisions. According to Stipek (2002), motivation is a psychologically complex issue and generally accepted as one of the most important factors that determine the rate and success of any human activity and this is why researchers have focused on those factors that motivate learners. Motivation according to Meece (2006) refers to choices people make as to what experience or goals they will approach or avoid, and the degree of effort they will exert in that respect. Motivation energises and guide $s$ behaviour towards reaching a particular goal in life. Modern theories of motivation (Stipek, 2002; Eccles and Wigfield, 2002; Meece, 2006) focus more on relation to the individual's beliefs, values and goals with action. Raburu's (2000) study of secondary students in Kenya highlights the relationship between 
positive attitude and intrinsic motivation of students to higher academic achievements.

Eccles and Wigfield (2002, p.112) highlight on the distinction between intrinsic and extrinsic motivation. When individuals are 'intrinsically motivated, they engage in an activity because they are interested in and enjoy the activity and when extrinsically motivated, individuals engage in activities for instrumental or other reasons, such as receiving a reward'. The role of gender in shaping achievement motivation has a long history in psychological and educational research (Meece, 2006). Studies on achievement motivation theories have been used to explain why adult women and men differed in their educational and occupational pursuits including attribution, expectancy -value, self-efficacy and achievement goal perspectives. Across all theories, findings indicate that girls' and boys' motivation-related beliefs and behaviours continue to follow gender role stereotypes (Stipek, 2002).

Family environment can influence self-efficacy through parental support and encouragement. Parents can nurture and support their children, while stimulating their curiosity and encouraging self-discovery to positively affect self-efficacy. This promotes intellectual development of the children (Eccles and Wigfield, 2002). Researchers (Raburu, 2000; Eccles and Wigfield, 2002) have further demonstrated that male and female adolescents differ not only in their interests, attitudes and plans for the future but also, in their self-confidence and self-evaluation.

\section{Theoretical Framework}

The present study was guided by a feminist perspective as it focuses on the participatory patterns of men and women in order to generate a more realistic picture of the situation. Onsongo (2005) in her study of women managers in Kenyan universities highlights that women are not given similar opportunities to men in social, economic, political and academic issues. Thus, her study concludes that higher institutions of education in Kenya are not gender neutral. A feminist perspective poses gender as a crucial category of analysis, with the intention of improving the understanding of how gender influences relations between men and women (Bensimon and Marshall, 1997). My main reason for exploring women academics' career experiences in Kenya from a feminist perspective is that, researchers (Morley, 1999; Bagilhole, 1993a; Bagilhole, 1994; Deem and Ozga, 1997; Hearn, 2001) have demonstrated that work in higher education institutions is highly gendered. For example, Hearn (2001, p.71) observes that there is a male numerical and cultural dominance in western universities that results in the universities and academic life being 'highly gendered organizationally, structurally and practically'. Hearn (2001, p.71) further identifies three features characterizing gendered structures of universities in most western countries as:

1. The exclusion of women from university education for a long time.

2. Men continuing to dominate the top positions of universities in most disciplines and management positions.

3. Higher status universities being more male dominated.

A feminist perspective fits for the present study because it problematises these gendered relations in universities so as to understand the taken for granted relations between men and women which have led to inequalities in the distribution of resources and opportunities (Delamont, 2003). By using a feminist perspective, the study is able to identify the gendered consequences of seemingly gender neutral policies and practices in the three universities in the present study. A feminist perspective therefore, enhances the argument that in the process of career advancement in the three universities the supposedly neutral gender blind policies and practices produce different results in the promotion of men and women academics (Bensimon and Marshall, 1997).

The gendered nature and the male cultural dominance of universities has led feminists like Deem and Ozga (1997) to conclude that a variety of interacting factors affect women's promotion, their career progress and because of the gendered nature of universities, women must show outstanding abilities if they want to be appointed to higher ranks. The underlying framework for this points out that, the forces of patriarchy which pervade the majority of African societies skew the balance of rights to mainstream development in favour of the male gender (Tamale and Oloka-Onyango, 2000).

\section{Research Questions}

The research main research question for this study:

What in the experiences of the women academics in Kenyan universities have contributed to their career success?

In addressing the above question, subsidiary questions are also addressed:

1. What motivational factors, personal attributes and skills have been critical in women academics' careers?

2. What significant contributing factors are perceived to have been barriers, if any, to career advancement of women academics? 


\section{Research Methodology}

The present study adopted a qualitative research design using an in-depth face- to- face interviews (Creswell, 2014). A purposive sampling (Mason, 2012) was used, establishing a link between the research questions and the sample. The researcher interviewed a sample of sixteen women academics with a prior pilot study of two, who formed part of the respondents in the final research. The sample consisted of two Professors, two Assistant professors, five Senior Lecturers, six Lecturers and one Assistant Lecturer. Since Kenya has few female academics. I selected respondents from three universities (two public and one private) as I was afraid that one university alone would not have had the adequate number. Letters were sent to all female academics with the ranks of lecturers to professors. I decided on the number sixteen to allow variety women academics' experiences. The study could not ensure a spread of respondents in all departments across all disciplines but respondents came from different departments.

The women academics included in this study were from different backgrounds in terms of age, academic interests, teaching experience, roles with their institutions and family backgrounds (married with children or single). Their ages ranged from twenty nine to fifty eight years. Eight women academics were in their forties, five in their fifties, two in their thirties and one in her late twenties. A semi-structured interview guide was used to ensure that most/all topics were covered, and allowing for in-depth expression of feelings. The interviews were conducted in English. Each interview lasted between forty five minutes to one hour. All interviews were audio-taped. Anonymity was maintained by allocating the respondents' synonyms W1 to W16 as express in (Creswell, 2014).

\section{Results}

\subsection{Motivational Factors}

Research Question 1 asked, 'What motivational factors, personal attributes and skills have been critical in women academics' careers?" Modern theories of motivation (Stipek, 2002; Eccles and Wigfield, 2002) relate the individual's beliefs, values and goals with actions. In this context, the beliefs about competence, expectancy for success, intrinsic and extrinsic motivation became relevant to women academics' careers. Socio-economic, intrinsic motivation, family, gender, role models and culture were among the factors cited to have motivated the respondents in the present study towards joining and staying in academe.

\subsubsection{Socio-economic/Escape from poverty}

An expression from $\mathrm{W} 10$ is an indication that through education, she could be alleviated from poverty:

I wanted to escape from poverty and to me, education was the only way out, there were no girls in my village of my age in school- all had either been married or got pregnant while in primary school. Thanks to my father and mother for their support for my education.

Respondents W10, W11, W16 reported that they wanted to 'escape from poverty', a form of extrinsic motivation according to (Eccles and Wigfield, 2002). Other respondents reported having been intrinsically motivated as expressed in the next section.

\subsubsection{Intrinsic and Extrinsic factors}

Eccles and Wigfield (2002, p.112) explain that when individuals are 'intrinsically motivated, they engage in an activity because they are interested in and enjoy the activity, while when extrinsically motivated, individuals engage in activities for other reasons such as receiving a reward', a feeling expressed by several respondents in the present study. Most respondents expressed having had intrinsic motivation to pursue their careers.

Intrinsic factors in this context include the attributes of being self-driven, love for reading, a sense of accomplishment and personal growth. Extrinsic factors on the other hand refer to rewards such as salary and job security. Intrinsic rewards are more satisfying and motivating than extrinsic rewards. Eccles and Wigfield (2002) agree that behaviour is influenced by personal factors (motivation or internal factors) and by environmental factors (external or outside influences).

W13 expresses different forms of intrinsic motivation: 
A perfectionist I think I am, I wanted to work and live my full potential, express and share my ideas, publish, speak for other women, be visible through publication.

A similar form of intrinsic motivation of being 'self-driven' and 'fulfilling a dream' was shared by W1:

\begin{abstract}
I am a self-driven person, I knew what I wanted to do, I knew I wanted to be around books. Being in academia has just fulfilled my dream and ambition. As a young child with a mother as a teacher, I developed an interest in reading story books.

Self-drives are different forms of intrinsic motivations as expressed by W7: I'm a self-motivated person, I enjoy my work'.

Similarly, W3 expressed that it was her self-driving forces that pushed her into joining academia, to fulfill a personal interest:
\end{abstract}

Being ambitious, I wanted to move up the professional rank, so I joined the university, a place where my ideas could be acknowledged. That was my driving force, to read hard, get a job at the university where I could express my ideas freely, and publish.

Another dominant attribute among the women academics is the passion for knowledge and the discovery of new knowledge. As students, some of them were bright, hard working and eager to learn. Another form of intrinsic motivation was expressed by W11, whose love for teaching and achieving a prestigious social status drove her to joining academia:

I love teaching and wanted to live my dream... the prestige of being called a Prof., being read about, publishing books and articles.

W1 expression of her love for teaching and a passion for reading could have a positive impact on students and the community:

I love what I'm doing, I enjoy reading and this has influenced my career choice. I can't divorce my work from my passion of reading. It's not that I wanted to lecture but, I knew I would end up in an academic environment.

Personal effectiveness, passion for reading and lecturing as expressed by W1 are strong motivators. For Principals in Pakistan studied by Nyangaga (2007), their key motivator was the opportunity to help students in the classroom. Women in educational leadership frequently cited internal factors as motivators (Coleman, 2001).

The construct of self-concept is a general term that describes a person's self image. According to career theorists such as Holland (1997), this construct plays a significant role in career development of an individual. As the person becomes aware of his or her self-concept, a realisation of requirements to certain occupations and experiences that fits with a particular self-concept. The respondents compared their self-concepts to various core values, roles and selfefficacy (Bandura et al., 2001).

Self-efficacy was interpreted by the respondents as referring to the personal judgement of their capabilities to produce desired outcomes in accordance with the roles and responsibilities that they had assumed. The evidence from the respondents is an indication of how their academic efficacy was affected by the past achievements, encouragement from parents, teachers, and the expectation of self. Socialisation and achievement experience play an important role in motivation. The child's home environment help to shape their competency beliefs and interest (Bandura et al., 2001).

\title{
5.1.3 Culture and Gender
}

Another significant motivational factor in career decisions to most respondents was their gender and cultural attitude. Both factors had a great influence on the respondents' self-image, others' perceptions of them as academics and as women. Parents reinforce gender roles through socialisation (Eccles and Wigfield, 2002).

Perceptions of gender inequality in a society that is patriarchal had driven some of the respondents like W11 to prove their abilities as she asserted:

I wanted to fulfill my mother's dream, her withdrawal from school at class five just because she was a woman, to be married off became a strong motivation to me to pursue my education and career to the 'sky' in my mother's words. My mother's story has always been an inspiration to me. She regularly re-told the story as if it was happening live each time I came from, and when going to school.

Because of the negative gendered cultural experience, W3 vowed to change her life and career decision to join academia and staying unmarried, as she expressed: 
I wanted to be my mother's 'protector'. My dad died when I was 17 years and my uncles took everything, left her with nothing! We are a family of 8 and all girls. To them, Girls are not children. I vowed to read to the highest level possible and promised myself to disapprove my uncles' cultural beliefs about women. It is this negative attitude and treatment to my mother that changed my preference of career to marriage. I am 46 years old and unmarried.

The comments below confirm the norm of marriage over education in the Kenyan society. Like other unmarried academics, W3 seems to have gone against the cultural norm, thus, facing resistance from her uncle through his comments:

\footnotetext{
...being a woman is only a biological sex factor and should not be used to discriminate in other areas of social life and rights, once my uncle commented, 'no one will ever marry you with those degrees'. I told him I would rather a degree to a man! I hold a PhD, of which I'm proud of.
}

The experiences of W11 and W3 confirm that culture formed the backbone of their motivation towards academic and career progress. They wanted to blow the wind of change on the gender attitude about women's education and marriage in Kenya. Expressions from the respondents in the present study show how ingrained the cultural attitudes are on women in the Kenyan society and it's through academe that the women hope for change.

\subsection{Challenges/Barriers to Career Advancement}

In answering, research question 2 asked, "What significant contributing factors are perceived to have been barriers, if any, to career advancement of women academics?", research in Canada, Australia, Europe, North America and Africa (Acker and Armenti, 2004; Currie et al., 2000; Wolf-Wendel and Ward, 2003;Kamau, 2004) show that women experience considerable conflicts and tensions when combining work and family responsibilities.

\subsubsection{Family-Career conflicts}

The comments from W6 highlight the impact of conflicts and tensions between being a mother, wife and pursuing a career:

I did Masters in United Kingdom and PhD in India. While studying for the MA I had 3 children and ten years later PhD, 4 children .I kept on asking myself, Do I go, or don't I go? I contemplated, while my husband repeatedly asked me. "Why can't you do the courses in Kenya?

In making a definite choice of career over marriage, W1 was conscious of being one of a few (the lone female) women applying for promotion and talked of male negative attitude, highlighting the impact of her gender especially in management. Like, W1 and W3, W7's priority was career over the family, postponing marriage due to the difficulties of combing both roles. However, a conscious choice to marry, not to have children, or to be single mother is a choice that disrupts normalized path of true motherhood and requires the courage to be different in a patriarchal society like Kenya.

Respondent W1 indicated that there is a 'cultural stigma' associated with being single in Kenyan society. She reported some of the negative comments from her colleagues:

When I call for meetings, sometimes I could hear some of my male colleagues (old guards) saying in the corridors of my office- 'let's go and hear what that girl has got to tell us'. In this culture, since I'm not married some men feel I don't deserve this administrative position as I lack a family which to them goes with wisdom.

In line with the present study, Armenti (2004b, pp. 217-218) in her study of nineteen women academics in a Canadian university found out that some older women academics were planning their pregnancies to deliver the babies in the month of May before obtaining tenure, scheduling motherhood, in what was referred to as the "May Baby Phenomenon' that is, having babies in May, or anytime in the Spring or Summer (a pre-tenure baby). A 'post-tenure Baby Phenomenon' was a situation where the women academics planned having babies in December after securing tenure. The young women had to hide their pregnancies during interviews, "Hidden Pregnancy Phenomenon' for the sake of obtaining tenure. In addition, the expression from a woman academic in (Acker and Armenti, 2004, p.10), shows a significant family and work tension, 'if I walked around pregnant, that would be my doom'. In her study, younger women academics were either childless, or unmarried. 
The struggle to balance family and career roles by women academics in the present study is diagrammatically illustrated in Figure 1 in the next section.

Figure 1: Kenyan Women Academics Balancing Family- Career

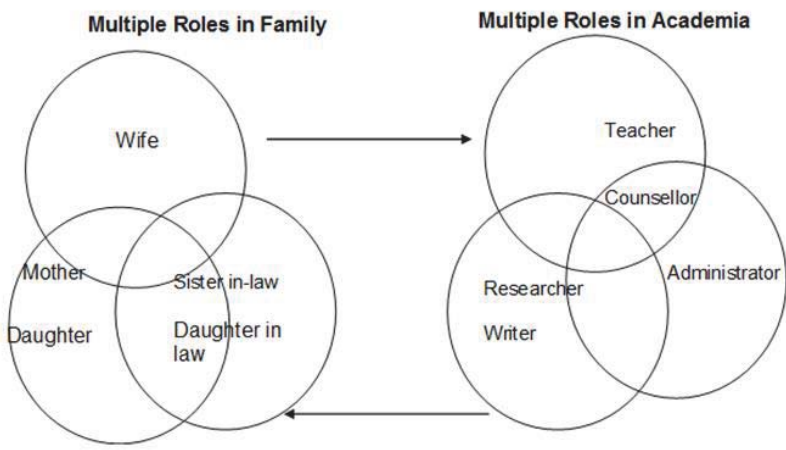

Figure 1 illustrates the multiple roles in family and academia that the Kenyan women academics struggle to balance and to accomplish. The women academics interviewed reported playing the roles of a; wife, mother, daughter, daughter inlaw and sister in-law while at the same time have to fulfill the career roles of being a; teacher, counselor, researcher, writer and administrator among others. For most of the respondents, balancing these roles result in inevitable conflicts and tensions.

\subsubsection{The University Culture}

This study refers to the university culture as the dominant culture or the practices, beliefs, and attitudes of the organisation. Furthermore, other researchers (Currie et al., 2000; Currie et al., 2002) describe the universities as greedy institutions and links this to an elite masculinist culture which thrives at and near the top of organizations.

W13 explained how she was made to feel irrelevant to the decision-making process:

...during the meetings with my male colleagues, I always smell a rat, from their discussions, I could feel they had already had another meeting ('the meeting before the meeting') prior to the one I attend... some decisions seem to have been made without me... I just guess in the pub over drinks...but in my absence.

Like many other women I interviewed, W6 expression suggests that decisions are already made by those in the male power networks and in favour of those who sing the correct tune:

...I can describe the university work environment as 'indifferent'- nobody is ready to mentor you and appointments depend on 'who knows who' or 'whose tune you sing'-not purely on merit. I have pulled myself up, my own effort, no one has helped me. It's been 25 year of hard work in academia.

Similarly the 'old- boys' network is echoed by W13 and indicates how women are not usually privy to decisions made outside the work setting, such as over lunches:

...the 'old-boys' network' and 'male-dominance' is practiced in this university. Women do not join their male colleagues for lunch... will ring your husband to tell him you have a relationship, gossips. Women are locked out of promotion and scholarship discussions, many of which take place during such social interactions... a feeling of 'academic isolation'. You can't escape it. The boys are in every committee.

W9 explained the tactics of exclusion, often disguised and (difficult to expose). She saw them as an indicator of an unhealthy working environment:

Men sit in their corners for tea while isolating women... exclusion of women from informal academic discussions and opportunities... this male attitude- 'go join other women over there'. 
Delamont (2003) too points out the gendered relations in universities and the inequalities in the distribution of resources and opportunities as expressed by W4:

....as a young mother, I lack child care facilities. There have been efforts on gender policy but not in practice and implementation. .... it's not easy to realise. ... on the surface everything seems fine. I say the institution has its positive points of allowing its faculty to attend conferences with no discrimination on gender.

W3 often expressed a feeling of being the 'lone female' especially at leadership meetings:

... the Kenyan universities are too 'male- streamed' in its recruitment, promotions, and committees..., need to be inclusive of more women, that's why I am a head of an Institute, my department is purely masculine, it, its too bold... very much male-dominated staff... the academic loneliness... why do I feel a foreigner and an outsider within my own institution? ... where are other women? I feel so isolated especially, as I have climbed the career ladder to management position.

Onsongo (2005) also found that female leaders feel isolated in an environment where the norm is for men to be in leadership as illustrated by W3 above. The experiences of W3 confirm the findings of an earlier study by Kanake (1997, p.63) on Kenya public universities where promotions depended on people's relationships with the top management rather than on competence as shown in the quotations below:

.... the university is based on social groups and members try to join the clubs of important people like the Vice Chancellor and the Deans in order to create good relations... staff who do not belong to these clubs may not get a promotion or opportunities even if they are qualified.

\subsubsection{The Cultural Expectations of Women Academics}

Data from this study suggests that the division of labour along traditional lines greatly influence women and men's perceptions of their gender roles. On women's perceptions of gender roles, Armenti (2004a) observes that where women have been successful in reaching the top professional ranks, their perceptions of expectations as women academics influence their behavior.

The cultural expectation of women in the Kenyan society is the norm of marriage at an early age, bringing up a family and domestic responsibilities. This determines how some women plan to go about performing academic responsibilities. Respondent W10 shared her perception:

I am a young mother with three small children, forcing me to forfeit attending conferences abroad and even at times late hour academic discussions with colleague as I have to rush home to attend to the children.

W1 in a similar context cites cases of cultural attitude about age and gender as a barrier to women's career advancement:

I'm one of the youngest (37 years) women to hold such a leadership, director of a campus and single- unmarried. Comments include, I am a VC's errand girl ...others think that there are sexual favours attached to all my promotions.

Another experience of a cultural/gender stigma is shared by respondent W3:

At one of the workshops with Principals of schools, I remember I introduced myself saying my first name. Later in the discussion, one of the male Principals asked if I had a PhD, and his response was, 'that's why men fear you'...I'm single and 46 years old.

It is evident from the words of W1 that gender, age and single status intensify the stereotypical- perception on women:

...the age, entwined with being single and a woman is a dilemma or rather has become an obstacle to progress. I would call this a 'triple cultural stigma'. In this culture it is assumed that wisdom comes with age and only to men or women who are married. To me, this should not be extended to the world of academia which should be about production.

On the other hand, W1 argues that there is a positive side of being single in academia:

...when I compare myself to many women with children, I consider myself light. I do not have the 'burden' in quotes of 
children or a husband. If I want to do my work, attend conferences, what worries me is just my work.

W1 felt that it was hard to separate attitudes towards her as a woman from attitudes to her position as a director. The reactions of men when reporting to a young female director reflected that culture accustomed to a traditional command and control:

\begin{abstract}
...the delicate balance comes in with the cultural attitude and assumption. As a director, whenever I call for meetings, I often hear older male colleagues (old guards) refer to me as Nyakoni (this girl) - in a derogatory manner - but I laugh it off. "Let's go and hear what that girl has to tell us"- that kind of thing- seeing me as too young, a woman, and who is unmarried. As a woman ... and at what level should one be taken seriously- It's difficult to divorce the three issues- I expect people to see me as a director, young as I am ...just a very delicate balancing. Being unmarried in Kenyan culture...you just remain a girl as far as they are concerned in this culture...those 'old norms'
\end{abstract}

In reporting a gender discriminatory experience, another respondent W3 who is unmarried had this to say:

Being a woman and single in this culture could be a hitch to one's career. It all began as I bargained on salary during my interview... I remember being asked by a man in the panel why I needed more money yet I'm single with no family responsibility ... the only woman in the panel seemed overpowered by the many men.

The experience of W12 in support further highlights the strong effects of culture on women's education in Kenya, showing the importance upon marriage over education:

...my parents organised to marry me off to someone without my consent ... after my A-level exams, I got to know at night an sneaked out... thank God I passed my exams and was admitted to a public university. I never saw my parents for 5 years...I told my story to a pastor of my church and many others. I hold PhD... married with three children. I strongly advocate and promote girls' education ...I run different community programmes in my village to promote girls' education.

Although this could be an isolated case, such practices as experienced by W12 still exist in some communities in Kenya in 2010. A 10 year old girl who had been married to an old man as a second wife cried; 'I did not want to get married. I wanted to continue with my education but my father forcefully married me off to that old man' (Benyawa, 2010, p.1).

In the above scenario, culture is portrayed in a double fold; on one hand, it negatively impacts on W12's academic and career journey, while that in itself has been a motivational factor towards achieving her success in academia.

\title{
6. Conclusion
}

The study reveals how the family environment influenced the self-efficacy of the respondents as their parents nurtured and supported them as children while stimulating their curiosity and encouraging self-discovery (Eccles and Wigfield, 2002). Intrinsic and extrinsic motivation, poverty, gender and culture motivated women academics in this study to join academe. The dominant attribute of passion for knowledge and discovery of new knowledge, a sense of self-motivation cited by different respondents showed a sense of intrinsic motivation according to (Eccles and Wigfield, 2002). Some respondents expressed feelings of personal satisfaction, being self-driven, and wanting to achieve dreams as motivations to joining academe. In addition, some women academics wanted to join academia as a way of escaping from poverty. Their parents urged them to read hard so that they would earn money to alleviate the families from poverty- a form of extrinsic motivation. Another motivating factor to joining academe was culture and gender. Some of the respondents reported that they wanted to blow the wind of change because of the practices of gendered inequalities and stereotypes in the Kenyan society.

The findings of this study reveal that, the sixteen women academics interviewed are juggling with combining family responsibilities and career expectations which resulted in inevitable conflicts and tensions. Some of them reported having postponed marriage for career, while others sacrificed their careers to attend to family responsibilities. The women academics are in addition not only working hard, but harder. To survive in academe, the women studied have to research and publish as this is 'pegged' to promotion in the universities where they work. Another common slogan in their institutions is 'publish or perish'. Despite working so hard, their progress continue to remain slow, in a reward system that they argue, does not favour them, and without sufficient recognition of their hard work. These findings add weight to research previously carried out on family-work conflicts (Armenti, 2004b: Acker and Armenti, 2004; Forster, 2001). The 
women in the present study emphasized the influence of a culture that continues to lay emphasis on their greater domestic responsibilities. Having internalized and accepted their roles as mothers and wives, they devote their time to domestic responsibilities even if this slows down their career advancement.

The findings of this study confirm that women academics still struggle to overcome the deeply embedded sociocultural and structural challenges to survive in these particular universities in Kenya and presumably, all others (see details in Table 1 on the under-representation of women faculty). From a feminist critical policy analysis perspective, academic careers contribute to a gender regime in universities because they remain structural, being male-dominated and being the beneficiaries of scholarships (Armenti, 2004a). The structure of the university has not been inclusive of women's needs in terms of child care facilities, women-friendly timings, promotion criteria, old-boys networks and clubs (Forster, 2001). Rather than changing the structure, women academics have been immersed into the already existing male-style university structures. In addition to the above factors, the respondents expressed feelings of academic 'isolation', 'outsiders', 'the lone female', 'out-casts' in academe combined with 'chilly climate', 'old-boys networks' from the universities result in a situation where women continue to be disadvantaged in their career progress.

Being a primary family responsibility, women in Africa carry dual burden of a mother and a wife while at the same time trying to accomplish their career obligations (Tamale and Oloka-Onyango, 2000). On the basis of this analysis, university policy makers should be inclusive of women academics' family needs and the study highlights important issues affecting women. The study has enhanced awareness on gender issues among colleagues, institutional cultures, and such awareness could improve workplace relationships. Of significance for consideration is the cultural attitude and the gender role expectations of women that persists in the Kenyan society. The findings of the present study reveal the cultural impact and its contribution to the slow progress of women academics' careers.

Further research might refine the present theory and or enhance generalisability by expanding and varying the sample population. For example, research could confirm or vary the results suggested here by carrying out in-depth interviews with a larger pool of women academics in Kenya, or women academics in other parts of the world. Future research could also compare how female academics from different cultural backgrounds make selective use of their dominant attributes to achieve their career success. In addition, further research on female academics in Higher Education could be undertaken in specific areas of conflicts between family and work, coping with multiple demands, university cultures, mentoring and networking.

\section{References}

Acker, S. and Armenti, C. (2004). Sleepless in academia, Gender and Education, 16, 3-24.

Armenti, C. (2004a). Gender as a Barrier for Women with children in Academe, The Canadian Journal of Higher Education, 34, 1-26.

Armenti, C. (2004b). May Babies and post-tenure babies: maternal decisions of women professors, Review of Higher Education, 27, 211-231.

Armenti, C. (2004c). Women faculty seeking tenure and parenthood: lessons from previous generations, Cambridge Journal of Education, 34, 65-83., http://www.standardmedia.co.ke/women/InsidePage.php?id=1144024660\&cid=450\&

Bagilhole, B. (1993a). How to keep a good woman down: An investigation of the role of institutional factors in the process of discrimination against women academics, British Journal of the Sociology of Education, 14, 261-274.

Bagilhole, B. (1993b). "Survivors in a male preserve: a study of British women academics' experiences and perceptions of discrimination in a UK university", Higher Education, 26, 431-447.

Bandura, A. (1997). Self-efficacy: Toward a unifying theory of behavioral change, Psychological Review, 84, 191-215.

Bandura, A., Barbarranelli, C. and Pastorelli, I. (2001). Self-efficacy beliefs as shapers of children's aspirations and career trajectories, Child Development, 72, 187-206.

Bensimon, E. M. and Marshall, C. (1997). Policy Analysis for Postsecondary Education:

Benyawa, L. (2010). Girl 10, rescued from forced marriage, The Standard, 16 th March. http://www.standardmedia.co.ke/InsidePage.php ?id $=2000005748 \&$ cid $=4 \&$

Bunyi, G. W. (2006). Gender Equity in Higher Education in Kenya. Nairobi: Public Universities Inspection Board.

Coleman, M. (2001). Achievement against the odds: The female secondary head teachers in England and Wales, Gender Issues in Leadership, 33, 3-20.

Collins, L. H., Chrisler, J. C. and Quina, K. (1998). Career Strategies for Women Academics:

Creswell, J. W. (2014). Research design: Qualitative, quantitative and mixed method approaches. Thousand Oaks, CA: Sage.

Currie, J., Harris, P. and Thiele, B. (2000). Sacrifices in greedy universities: Are they gendered?, Gender and Education, 12, $269-291$.

Currie, J., Thiele, B. and Harris, P. (2002). Gendered universities in Globalized economies. Lanham, MD: Lexington.

Deem, R. and Ozga, J. (1997). Women Managing for Diversity in a Postmodern World. In: C. Marshall, (Ed.) Feminist Critical Policy Analysis II: A Perspective from Post-Secondary Education. London: The Falmer Press.

Eccles, J. S. \& Wigfield, A. (2002) Motivational Beliefs, Values and Goals Annual Review of Psychology, 53, 109-132. 
Forster, N. (2001). A case study of women academics' views on equal opportunities, career prospects and work-family conflicts in a UK university, Career Development International, 6, 28-38.

Gachukia, E. W. (2002). The Role of Higher Education in Empowering Women in Eastern Africa. Regional Training Workshop for Women and Higher Education Management.

Hearn, J. (2001). 'Academia, Management and Men: Making the Connections, Exploring the implications'. In: A. Brooks, and Mackinnon, A. (Eds.) Gender and the Restructured University: Changing Management and Culture in Higher Education. Buckingham: Society for Research in Higher Education and Open University Press.

Kamau, N. M. (2004) Outsiders Within: Experiences of Kenyan Women in Higher Education. Jenda: A Journal of Culture and African Women Studies, 6, 1-26.

Kanake, L. (1997). Gender Disparities among the Academic Staff in Kenyan Universities. Nairobi: Lyceum Educational Consultants Ltd.

Luke, C. (2000). One step up, two down: Women in higher education management in Southeast Asia. In: M. Tight, (Ed.) Academic work and life: What it is to be an academic, and how this is changing. Oxford: Elsevier Science.

Manya, M. O. (2000) Equal Opportunity Policy (gender): A means to increasing the number of female senior managers and decisionmakers at the university of Nairobi. MA Thesis. London: Institute of Education, University of London.

Mason, J. (2002). Qualitative Researching. London: Sage.

Mason, M. A. and Goulden, M. (2002). Do babies matter?: The effect of family formation on the lifelong careers of academic men and women, Academe, 88, 21-27.

Meece, J. (2006). Gender and Motivation, Journal of School of Psychology, 44, 351-373.

Morley, L. (1999). Organising Feminism: The Micropolitics of the Academy. London: Macmillan.

Morley, L. (2000). The micropolitics of gender in the learning society, Higher Education Europe, 25, 229-235.

Morley, L. (2006). Hidden transcripts: The micropolitics of gender in Commonwealth universities, Women's Studies International Forum, 29, 543-551.

Morley, L. and Walsh, V. (1996). Breaking Boundaries: Women in Higher Education. London: Taylor and Francis.

Muindi, B. (2011). Public universities to admit 24, 221 students. Daily Nation 24th February, 2011 http://www.nation.co.ke/News/Public+ universities+to+admit+24221+students+/-

Nyamu, F. (2004). Experiences in Gender Mainstreaming at the University Level: The East African Experience focusing on Egerton University in Kenya and Makarere University in Uganda. Tanzania: Gender Mainstreaming Workshop.

Nyangaga, J. A. (2007). Women in School Leadership: Exploring Gender Experiences in Becoming School Leaders. MA Thesis. Karachi: The Aga Khan University.

Onsongo, J. K. (2000). 'Publish or perish': An Investigation into Women's Access to Research and Publication in Kenyan Universities. MA Thesis. London: Institute of Education, University of London.

Onsongo, J. K. (2005). "Outsiders Within" : Women's Participation in University Management in Kenya. PhD Thesis. London: University College of London.

Onsongo, J. K. (2009). Affirmative action, gender equity and university admissions- Kenya, Uganda and Tanzania, London Review of Education, 7, 71-81.

Quina, K., Chrisler, J. C. and Collins, L. H. (1998). Career Strategies for Women in Academe: Arming Athena. Thousand Oaks: Sage.

Raddon, A. (2002). Mothers in the academy. Studies in Higher Education, 27, 387-403

Raburu, P. A. (2000). Students' Perception of the effect of Ability Grouping on their motivation: A study of two secondary schools in Kenya. MA Thesis. London: Institute of Education, University of London.

Siringi, S. (2009). Public varsities name 17,000 new students, The Daily Nation. 6th March. http://www.nation.co.ke/News//1056/542836/-/u330gw/-/index.html

Stipek, D. J. (2002). Motivation to Learn. Boston: Allyn and Bacon.

Tamale, S. and Oloka-Onyango, J. (2000). "Bitches at the Academy: Gender and Academic Freedom in Africa. In: E. Sall, (Ed.) Women in Academia: Gender and Academic Freedom in Africa. Dakar-Senegal: CODESRIA..

White, K. (2001). Women in the Professorate in Australia, International Journal of Organisation Behaviour, 3, 64-76.

White, K. (2004) The Leaking Pipeline: Women Postgraduate and early career researchers in Australia. Tertiary Education and Management, 10, 227-241. 